\title{
Characterization of Sulfur Compounds in MTBE
}

\author{
Mingqing Wu, Chunyan Chang, Tao Li, Jian Zhou, and Liping Zhao
}

Research Institute of Petroleum Processing, Beijing 100083, China

Correspondence should be addressed to Mingqing Wu; wumq.ripp@sinopec.com

Received 11 August 2014; Revised 23 October 2014; Accepted 4 November 2014

Academic Editor: Marten Ternan

Copyright (C) 2015 Mingqing Wu et al. This is an open access article distributed under the Creative Commons Attribution License, which permits unrestricted use, distribution, and reproduction in any medium, provided the original work is properly cited.

\begin{abstract}
A study is carried out on chemical constitution of sulfur compounds in MTBE and their formation mechanisms. These sulfur compounds are classified into three types: common sulfur compounds, newly formed sulfur compounds, and high boiling sulfur compounds. Common sulfur compounds which include mercaptans, low molecule sulfides and disulfides, are directly from C4, one of the stocks for production of MTBE. The newly formed sulfur compounds, with one sulfur atom and five or more total carbon atoms in one molecule, are mainly tert-butyl methyl sulfide and tert-butyl ethyl sulfide, thioetherification products of thiols with butenes. Many high boiling sulfur compounds, including polysulfides such as dimethyl trisulfide, multisulfur heterocyclic compounds such as 3,5-dimethyl-1,2,4-trithiolane, and oxygen-containing sulfur compounds such as 2-methoxy-3-methylthiobutane, are also found newly formed in the processes of LPG refining and succedent etherification reaction for producing MTBE. Polysulfides are additional products of elemental sulfur to disulfides, and other high boiling sulfur compounds may be formed by thiols reacting with dienes.
\end{abstract}

\section{Introduction}

Methyl tert-butyl ether, or MTBE for short, is used as high octane number component for gasoline, excellent solvent, and stock for cracking preparation of polymerization grade isobutene and so forth. It is approved as the largest group of nonhydrocarbons blending component in gasoline in China. Production capacity of MTBE in China was over 10MT in 2013.

Organic sulfur compounds are acknowledged to be harmful to all fuel oil products including gasoline. So in less than 30 years, limits to sulfur contents in various petroleum products have been greatly reduced. For example, the sulfur content allowance in gasoline which met EN228-1993 (European Standard: Automotive fuels-Unleaded petrolRequirements and test methods) must be less than $0.10 \%$, but sulfur limit in EN228-2009 must be less than $0.0010 \%$, with a reduction of $99 \%$ in 15 years. Another case is automotive LPG, expressed in EN589 (European Standard: Automotive fuelsLPG-Requirements and test methods). In EN589-1993, total sulfur content is limited to less than $0.0200 \%$, but in EN5892008 the sulfur content limit is reduced to no more than $0.0050 \%$.
In China, MTBE is the most important gasoline blending component; its volume in gasoline can be up to 14.9 (v)\%. The sulfur content of "Gasoline for Vehicle in China" was allowanced no more than $0.20 \%$ before 2000 , and it is now limited to no greater than $0.0050 \%$ and will be limited to less than $0.0010 \%$ before 2017 [1]. But sulfur content in MTBE produced in China is usually $0.0040-0.1000 \%$, some even over $0.2000 \%$. Sulfur content is now the main bottleneck restricting MTBE as gasoline blending component.

MTBE is mainly synthesized industrially through the etherification reaction of methanol with isobutene existent in mixed $\mathrm{C} 4$ hydrocarbons under the catalysis of acidic catalysts, such as strongly acidic cation exchange resins. The mixed C4 hydrocarbons are usually obtained by distillating liquefied petroleum gas in the gas fractionation unit, containing isobutene, butane, 1-butene, and 2-butene besides isobutene. Experiences show that $80 \%$ or more of sulfur in LPG will be concentrated in MTBE. So usually sulfur contents in MTBE are 5 or more times as in refined LPG.

Some studies have been carried out on sulfur compounds that existed in LPG in China and abroad [2-8]. But there have been only a few researches on how to remove sulfur compounds from MTBE $[9,10]$. There are fewer investigations 
on sulfur compounds in MTBE. Therefore, it is necessary to make clear structures and forming mechanisms of sulfur compounds in MTBE. Understanding of these compounds will be beneficial for making practicable programs to reduce sulfur content of MTBE.

\section{Experimental}

2.1. Instruments and Methods. Gas Chromatography Agilent GC7890, equipped with a 50-meter-long PONA column, dual detectors of SCD (sulfur chemiluminescence detector), and FID (flame ionization detector), was applied to acquire sulfur signal or both sulfur and organic component signals simultaneously, operated at the following GC temperature program: initial temperature at $35^{\circ} \mathrm{C}$, ramped at $3^{\circ} \mathrm{C} / \mathrm{min}$ to $180^{\circ} \mathrm{C}$ at $2^{\circ} \mathrm{C} / \mathrm{min}$ with a final hold of $5 \mathrm{~min}$.

Gas chromatograph-mass spectrometer (GC-MS) is composed of Agilent GC7890B and 5977A MSD, used to determine chemical structures of most sulfur compounds in MTBE. Gas chromatograph-high resolution mass spectrometer (GC-HRMS), composed of Agilent GC7890 and JEOL AccuTOF GCV High-Resolution Mass Spectrometer, was used to confirm molecular formulae of some complicated sulfur-containing compounds in MTBE.

Total sulfur contents of all samples were obtained through TS3000 UV total sulfur analyzer, which is provided by Thermo Fisher Scientific Inc., according to the method of SH0689 or D5453-12 (Standard Test Method for Determination of Total Sulfur in Light Hydrocarbons, Spark Ignition Engine Fuel, Diesel Engine Fuel, and Engine Oil by Ultraviolet Fluorescence).

Infrared Spectrometer, Nicolet 6700, also product of Thermo Fisher Scientific Inc., was used to get IR spectrums of some samples. NMR (nuclear magnetic resonance) spectrometer of Varian Company, named INOVA $500 \mathrm{MHz}$, was used to obtain both 13C NMR and 1H NMR of samples.

MTBE synthesis equipment is a device provided by the Scientific Equipment Center of Research Institute of Petroleum Processing and was used here to simulate the formation of some trace sulfur compounds while MTBE is being synthesized under normal conditions.

2.2. Chemicals. MTBE samples from many refineries all over China were used for this study. Methanol, 90-120 mineral ether, and sodium hydroxide were analytical reagent. Isobutene, methanethiol, ethanethiol, dimethyl sulfide, isopropanothiol, tert-butanethiol, propanothiol, and isobutanethiol, thiophene were chemically pure. Cobalt phthalocyanine sulfonates were an industrial product provided by Huazhen Chemical Limited, Dongying, China.

\subsection{Experimentation}

Preparations of Disulfides in Sulfur-Free Solvent. Methanethiol, ethanethiol, isopropanothiol, propenothiol, and tertbutanethiol were dissolved in an aqueous solution of $10 \%$ sodium hydroxide with sulfur concentration of about $100 \mathrm{mg} / \mathrm{L}$ each. Cobalt phthalocyanine sulfonates were added in the solution at $100 \mathrm{mg} / \mathrm{L}$ and stirred vigorously for $10 \mathrm{~min}$.
Then a sulfur-free solvent (90-120 mineral ether) was added to the alkali solution with a volume identical to that of alkali solution and stirred vigorously for another $10 \mathrm{~min}$. The mixture was then settled down for $30 \mathrm{~min}$. The upper layer of mineral ether was the extracted layer and may contain corresponding disulfides which might occur in refined C4.

Simulation Synthesis of Sulfides in MTBE. Methanethiol and ethanethiol are dissolved in methanol at the concentration of $200 \mathrm{mgS} / \mathrm{L}$. The solution was then mixed with isobutene in a $\mathrm{N}_{2}$-replacement jar at $0.4 \mathrm{Mpa}$, with the molar ratio of methanol:isobutene equal to $1.1: 1$. The mixture was then passed through a bed loaded with macroporous cation exchange resin D006 at $65^{\circ} \mathrm{C}$, with a liquid hourly space velocity of $1.0 \mathrm{~h}^{-1}$. The output was collected in a jar cooled below $-10^{\circ} \mathrm{C}$. After the reaction, the output was flashed to remove the surplus isobutene and methanol at atmosphere and ambient temperature. An MTBE sample was obtained, possibly containing simulated synthesized trace organic sulfur compounds which remained therein.

Preparations of Polysulfides in Sulfur-Free Solvent. An unregenerated alkali for refining LPG was got from a refinery. It contained sodium hydroxide of $12.5 \%$, mercaptides of up to $22000 \mathrm{mgS} / \mathrm{L}$ of $\mathrm{CH}_{3} \mathrm{~S}^{-}$and $5600 \mathrm{mgS} / \mathrm{L}$ of $\mathrm{CH}_{3} \mathrm{CH}_{2} \mathrm{~S}^{-} .7 .3 \mathrm{~g}$ of sodium sulfide was dissolved in $50 \mathrm{~mL}$ of the alkali to get a concentration of $\mathrm{S}^{2-}$ about $60000 \mathrm{mgS} / \mathrm{L}$, and then about $5 \mathrm{mg}$ of cobalt phthalocyanine sulfonates was added and mixed vigorously while being exposed to the air for $30 \mathrm{~min}$. At last, $50 \mathrm{~mL}$ of $90-120$ mineral ether was used to extract possible newly formed fat-soluble substances in the alkali. It is expected that a series of polysulfides were contained in the extraction phase.

A calibration table of retention time $\left(T_{R}\right)$ in GC-SCD for individual sulfur compounds possibly existent in MTBE was obtained by using commercial standard substance or laboratory-synthesized sulfur compounds.

\section{Discussion}

MTBE is mainly manufactured from the etherification reaction of methanol with isobutene contained in mixed C4, which is usually bottom product in the gas fractionation device, with the refined LPG as the feed. Sulfur analysis for nearly 50 sources of MTBE shows that almost all sulfur compounds are originated from refined LPG, for sulfur contents of methanol used are usually less than $0.00005 \%$. So it is important to investigate how sulfur compounds are transferred from refined LPG to MTBE.

3.1. Calibration of Common Sulfur Compounds. Here common sulfur compounds are referred to as sulfur-containing compounds simply transferred from LPG or C4 to MTBE. These sulfur compounds may be directly from LPG stock or may be changed morphologies in LPG refining processes.

The GC-SCD/FID instrument is used to measure retention time of relevant sulfur compounds under the condition of 2.1. Standard sulfur compounds are valve-injected into the column cap of the GC. Retention time of these sulfur 
TABLE 1: Retention time of possible common sulfur compounds in MTBE.

\begin{tabular}{lc}
\hline Sulfur compounds & Rt, min \\
\hline Methanethiol & 5.71 \\
Ethanethiol & 6.90 \\
Dimethyl sulfide & 7.21 \\
Isopropanothiol & 8.20 \\
tert-Butanothiol & 9.45 \\
Propanothiol & 9.85 \\
Ethyl methyl sulfide & 10.06 \\
Isobutanothiol & 12.45 \\
Thiophene & 12.50 \\
Isopropyl methyl sulfide & 12.80 \\
Diethyl sulfide & 12.96 \\
Propyl methyl sulfide & 14.10 \\
Butanothiol & 15.20 \\
Methyl tert-butyl sulfide & 15.99 \\
Dimethyl disulfide & 16.97 \\
Isobutyl methyl sulfide & 19.50 \\
Ethyl tert-butyl sulfide & 21.20 \\
Methyl ethyl disulfide & 23.67 \\
Isopropyl methyl disulfide & 28.42 \\
Diethyl disulfide & 30.71 \\
Propyl methyl disulfide & 31.56 \\
tert-Butyl methyl disulfide & 32.13 \\
Methyl trisulfide & 34.31 \\
Methyl isopropyl disulfide & 35.18 \\
Diethyl trisulfide & 38.49 \\
tert-Butyl ethyl disulfide & 38.72 \\
Diisopropyl disulfide & 39.14 \\
Methyl ethyl trisulfide & 41.39 \\
Isobutyl ethyl disulfide & 41.63 \\
tert-Butyl isopropyl disulfide & 42.33 \\
Propyl isopropyl disulfide & 45.70 \\
Dipropyl disulfide & \\
tert-Butyl propyl disulfide & \\
Di-tert-butyl disulfide & \\
\hline
\end{tabular}

compounds is collected in Table 1. A unique problem is that thiophene has an almost same retention time as isobutanothiol. This can be solved through a Merox reaction in which isobutanothiol can be easily catalytically oxidized to heavier disulfide and thiophene cannot.

3.2. Common Sulfur Compounds in MTBE. About $50 \mathrm{MTBE}$ samples were taken from different refineries or at different time. Oxygen compound analysis showed that the concentration of MTBE for all samples was more than $95 \%$, with impurities mainly sec-butyl alcohol, tert-butyl alcohol, tertamyl methyl ether (TAME), and trace C5-C12 hydrocarbons. That meant all MTBE samples are normal.

All samples were analyzed through GC-SCD. Total sulfur contents were obtained by TS3000 sulfur analyzer. One of typical sulfur distributions in MTBE obtained by GC-SCD is

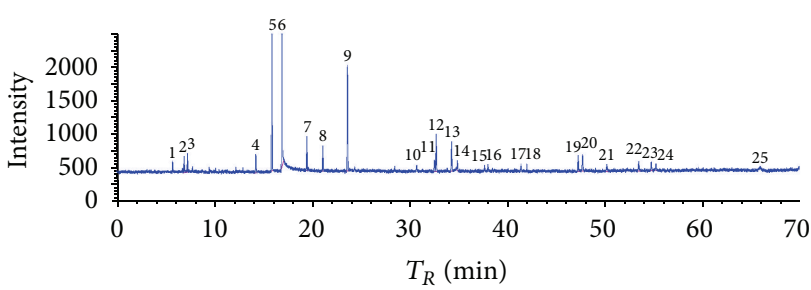

(a)

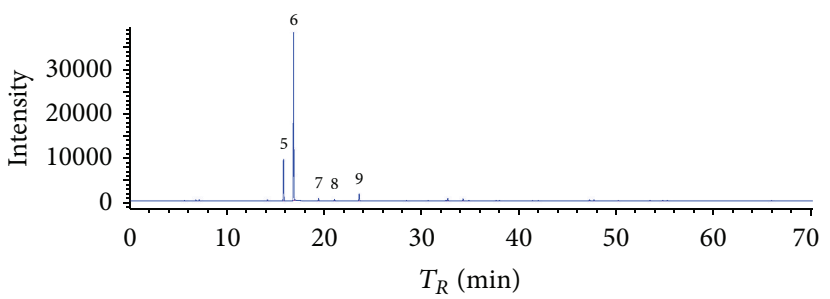

(b)

Figure 1: GC-SCD for sulfur compounds in MTBE05. (a) Amplified GC-SCD figure for MTBE05. (b) Whole GC-SCD figure for MTBE05. (1) Methanethiol; (2) ethanethiol; (3) dimethyl sulfide; (4) propyl methyl sulfide; (5) unknown; (6) dimethyl disulfide; (7-8) unknown; (9) ethyl methyl disulfide; (10) diethyl disulfide; (11-24) unknown; (25) elemental sulfur.

shown in Figure 1 (MTBE05). Results for five of these samples (MTBE01, MTBE02, MTBE03, MTBE04, and MTBE05 from different refineries) are listed in Table 2.

Figure 1(a) represents the whole GC-SCD for MTBE05 in Table 2, and Figure 1(b) represents its spectrogram 10 times amplified on the $y$-axis. Figure 1(b) shows that there are 5 significant peaks, peak $5,6,7,8$, and 9 , indicating the existence of 5 main types of sulfur compounds in the sample. In Figure 1(a), some more trace amount of sulfur compounds can be seen. Among these peaks, peak 1-4, 6, and 9 can be resolved as methanethiol, ethanethiol, dimethyl sulfide, propyl methyl sulfide, dimethyl disulfide, and ethyl methyl disulfide, respectively, referring to Table 1 . Other types of sulfur compounds need further research.

Many MTBE samples were analyzed in this way and much more types of sulfur compounds, most of which were often ignored before, were found.

It can be found in Table 2 that sulfur content and sulfur distribution of various MTBE samples are very different from each other. Most of sulfur compounds are dimethyl disulfide, ethyl methyl disulfide, and diethyl disulfide. There are seldom higher molecular disulfides in MTBE. Sometimes there are little lighter sulfur compounds such as $\mathrm{C} 1-\mathrm{C} 2$ thiols and C2C4 sulfides.

Disulfides have a formula as follows:

$$
\mathrm{R}_{1} \mathrm{SSR}_{2}
$$

where $R_{1}$ and $R_{2}$ are alkyl. Disulfides are the products of sweetening of thiols, forming in LPG refining process. In most cases, disulfides are the main forms of sulfur compounds in refined LPG or C4; therefore disulfides often account for main sulfur compounds in MTBE. However, In some extreme case, there are almost no common sulfur 
TABLE 2: Common sulfur compounds in MTBE.

\begin{tabular}{|c|c|c|c|c|c|}
\hline \multirow{2}{*}{ Sulfur compounds } & \multicolumn{5}{|c|}{ Sulfur forms, S\% } \\
\hline & MTBE01 & MTBE02 & MTBE03 & MTBE04 & MTBE05 \\
\hline Methanethiol & 0.00000 & 0.00000 & 0.00000 & 0.00000 & 0.00018 \\
\hline Ethanethiol & 0.00000 & 0.00000 & 0.00000 & 0.00016 & 0.00041 \\
\hline Dimethyl sulfide & 0.00000 & 0.00014 & 0.00000 & 0.00000 & 0.00046 \\
\hline tert-Butanothiol & 0.00000 & 0.00000 & 0.00000 & 0.00005 & 0.00000 \\
\hline Isobutanothiol & 0.00000 & 0.00000 & 0.00000 & 0.00008 & 0.00000 \\
\hline Diethyl sulfide & 0.00000 & 0.00000 & 0.00075 & 0.00000 & 0.00000 \\
\hline Isopropyl methyl sulfide & 0.00000 & 0.00000 & 0.00014 & 0.00000 & 0.00054 \\
\hline Dimethyl disulfide & 0.00005 & 0.02440 & 0.12556 & 0.01990 & 0.04910 \\
\hline Methyl ethyl disulfide & 0.00000 & 0.00106 & 0.05485 & 0.00200 & 0.00250 \\
\hline Diethyl disulfide & 0.00000 & 0.00000 & 0.00386 & 0.00041 & 0.00014 \\
\hline Propyl methyl disulfide & 0.00000 & 0.00000 & 0.00043 & 0.00000 & 0.00000 \\
\hline $\begin{array}{l}\text { Total common sulfur } \\
\text { identified }\end{array}$ & 0.00000 & 0.02560 & 0.18559 & 0.02260 & 0.05378 \\
\hline $\begin{array}{l}\text { Total common sulfur } \\
\text { identified, \% }\end{array}$ & 1.0 & 72.0 & 53.9 & 66.0 & 73.4 \\
\hline Total sulfur & 0.00524 & 0.03557 & 0.34443 & 0.03424 & 0.07329 \\
\hline Other forms of sulfur, $\%$ & 0.00519 & 0.00997 & 0.15884 & 0.01164 & 0.01951 \\
\hline
\end{tabular}

compounds in MTBE, as MTBE01 in Table 2. That means sometimes the LPG refining process produces no disulfides.

Some MTBE samples contain lighter sulfur components, such as methanethiol, ethanethiol, and dimethyl sulfide. These sulfur compounds can be controlled by improving alkali-washing condition (for reducing thiols), or adjusting stable adsorption condition (for reducing ethanethiol and sulfides), or optimizing operation conditions of MTBE catalysis distillation tower (for reducing all sulfur compounds with B.P. $<56^{\circ}$ C, B.P. of MTBE).

Of particular note is that in Table 2 there are many more other forms of sulfur compounds except common ones. These forms of sulfur account for about 30\%-50\%, occasionally over $80 \%$, of total sulfur as in MTBE01 and can never be ignored. They cannot be simply identified by deduction from sulfur compounds in refined LPG or C4.

When ultralow sulfur MTBE is requested, sulfur compounds with minor content in MTBE should also be investigated before making a scientific process to greatly reduce content of sulfur compounds in MTBE. It is necessary to investigate structures of other forms of sulfur compounds besides common sulfur compounds in MTBE listed in Table 2.

3.3. Research on Complicated Sulfur Compounds in MTBE. In Table 2, there are many other forms of sulfur compounds in MTBE besides common sulfur compounds. Sometimes they account for the majority of sulfur as in MTBE01. Analyses show that these compounds are seldom found in refined LPG or $\mathrm{C} 4$. They could be second reaction products of common sulfur compounds with some components in C4 under the etherification conditions for producing MTBE. It is necessary to investigate structures of these sulfur compounds.
3.3.1. Light Complicated Sulfur Compounds and Formations. These sulfur compounds cover $T_{R}$ in GC-SCD from $15 \mathrm{~min}$ to $60 \mathrm{~min}$. For the sake of research, they are classified into light complicated sulfur compounds and heavy complicated sulfur compounds to the limit of $T_{R}=32.0 \mathrm{~min}$ in GC-SCD. That means newly formed sulfur compounds with $T_{R}<32.0 \mathrm{~min}$ are light complicated sulfur compounds and those with $T_{R}>$ $32.0 \mathrm{~min}$ are heavy complicated sulfur compounds.

In Figure 1, peak numbers 5, 7, and 8 often appear in GC-SCD. Under certain circumstances, peak number 5 as in Figure 1 is even the strongest peak (as MTBE01).

For sample MTBE03 in Table 2, the peak intensity corresponding to peak number 6 in Figure 1 is very strong. So GC-MS is directly applied to carry out a fine analysis. Result shows that the most matching structure is as follows:<smiles>CSC(C)(C)C</smiles>

Its CAS registry number is 6163-64-0, nominated as 2methyl-2-(methylthio)-propane or tert-butyl methyl sulfide (MTBS). The structure is similar to MTBE except oxygen atom being displaced by sulfur atom:<smiles>COC(C)(C)C</smiles>

As is known to all, MTBE is synthesized industrially through etherification reaction as follows: 
(1)<smiles></smiles>

Methanol and ethanol can react with isobutene to form MTBE and ETBE under acidic catalytic condition. It is deduced that methanethiol and ethanethiol may also react with isobutene to form MTBS (methyl tert-butyl sulfide) and ETBS (ethyl tert-butyl sulfide), respectively, as the same mode of formation of MTBE and ETBE.

(2)

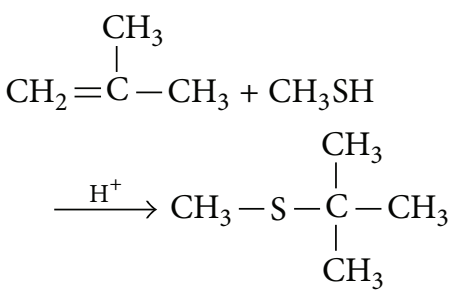

(3)<smiles>C=C(C)CC</smiles>

For confirming this deduction, a simulation test was carried out. About $200 \mathrm{mg} / \mathrm{kg}$ (by S) of methanethiol and ethanethiol is, respectively, added to absolute methanol. The methanol containing thiols was then mixed with isobutene, with molar ratio of methanol/isobutene about $1.1: 1.40 \mathrm{~mL}$ of D006 macroporous cation exchange resin was packed in a tabular reactor prepared for the reaction.

The mixture was then pumped up-to-down through the reactor with LHSV $1.0 \mathrm{~h}^{-1}$ and temperature of $55-70^{\circ} \mathrm{C}$. Product eluted from the reactor was collected in a cooled jar. The product was flashed at ambient temperature to remove unreacted isobutene and some possible thiols. The remained main substance was theoretically MTBE and is analyzed by GC-SCD to determine the distribution of sulfur compounds. GC-FID measurement showed that major component was MTBE.

Figure 2 is a comparison of sulfur compounds forms in methanol adding the thiols and in MTBE synthesized with the methanol and isobutene.

Obviously in the etherification reaction of methanol with isobutene to synthesize MTBE, thioetherification reactions of thiols with butene to form alkyl-butyl sulfides also concur.

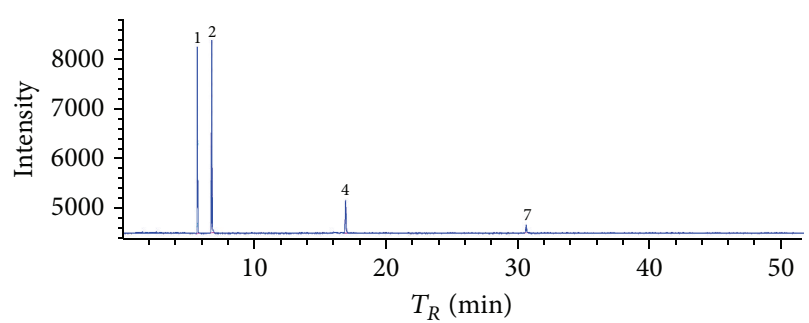

(a)

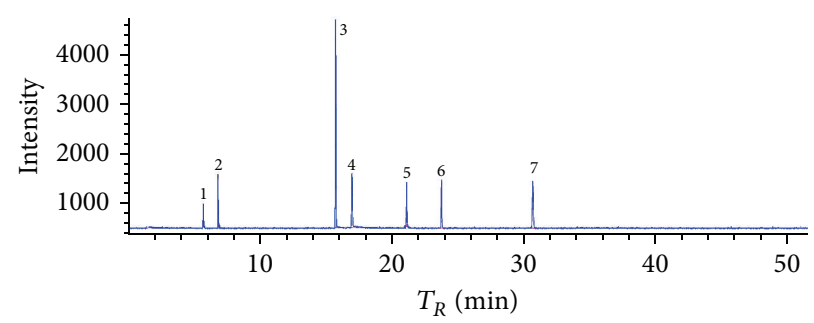

(b)

FIGURE 2: Sulfur compounds generated from the simulation test. (a) Before reaction: methanol containing trace methanethiol and ethanethiol; (b) after reaction: MTBE synthesized by using isobutene and the methanol. (1) Methanethiol; (2) ethanethiol; (3) tert-butyl methyl sulfide; (4) dimethyl disulfide; (5) tert-butyl ethyl sulfide; (6) ethyl methyl disulfide; (7) diethyl disulfide.

In other MTBE samples, structures as<smiles>CCC(C)SCC(C)C</smiles>

are also found by GC-MS ( $T_{R}$ at $19.20 \mathrm{~min}, 19.50 \mathrm{~min}$, resp., at the GC condition), but usually with lesser concentration. These newly formed alkyl sulfides may also be produced through thioetherification reactions of thiols with butenes similar to the reaction (2).

Increasing water content in methanol or (and) lowering etherification reaction temperature can reduce the production of these sulfides. But the effects are very limited. An easy and good way to avoid newly formed alkyl sulfides is removing thiols thoroughly from C4 or LPG in the process of LPG refining.

3.3.2. Heavy Complicated Sulfur Compounds. There are more or less heavy sulfur compounds in most of all MTBE samples under our research. For example, peak 11-24 in Figure 1 indicate existence of sulfur compounds with higher boiling point. Usually, their concentrations are often very low, and so close attention was not paid in the past. But it is still important to study their chemical structures for deep desulfurization of LPG and MTBE.

For about 50 MTBE samples analyzed by the GC-SCD, there are three circumstances about heavy sulfur compounds: 13 samples present heavy sulfur compounds as in Figure 3(a) and 17 samples present heavy sulfur compounds 


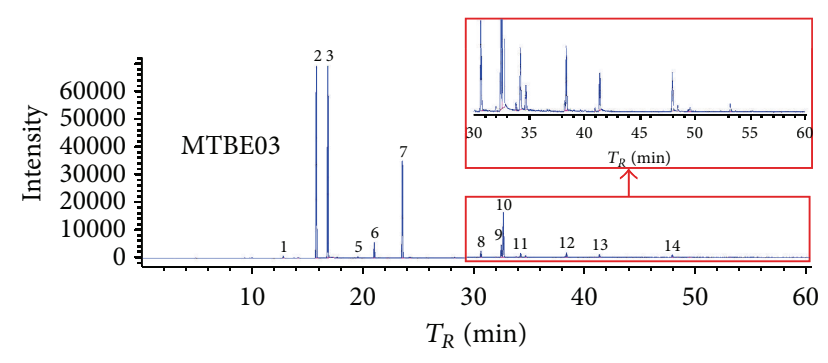

(a)

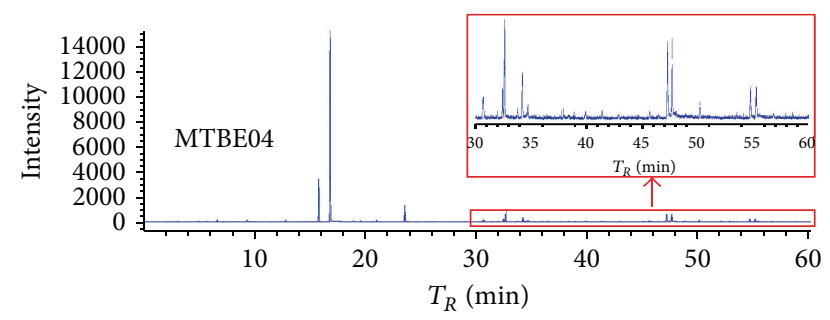

(b)

Figure 3: GC-SCD of MTBE from different refineries. (a) Sulfur distribution of sample MTBE03 in Table 2. (b) Sulfur distribution of sample MTBE04 in Table 2.

as in Figure 3(b). The other MTBE samples contain too few heavy sulfur compounds to have enough SCD signals for recognition.

Figure 3 is GC-SCD of MTBE03 and MTBE0 4 in Table 2. The enlarged area clearly shows that some heavy sulfur compounds exist in some MTBE samples.

It is found in GC-SCD figures that most of MTBE samples have a peak of $32.70 \mathrm{~min}$, as peak 10 in Figure 3(a). Furthermore, there is a smaller peak adjacent to the peak $32.70 \mathrm{~min}$, with retention time of $32.50 \mathrm{~min}$ and intensity of about one-third of the former.

Sample MTBE03 has very high sulfur content. It was distilled (first at atmosphere and then at gradually reduced pressure to ensure the temperature of liquid phase less than $100^{\circ} \mathrm{C}$ ) carefully to remove lighter fractions and leave heavier component. A GC-SCD analysis is carried for the heavier component. Figure 4 shows the comparison of signal obtained by SCD and FID for the heavier components in retention time between 20 and $40 \mathrm{~min}$. It is apparently found in Figure 4 that almost every SCD signal corresponds to a FID signal. So it can be considered that the heavier component obtained is almost a mixture of concentrated sulfur compounds.

Because of small amount of the concentrated sample, it is difficult to separate the heavier components further into individual sulfur compound. Instrumental methods of IR (Infrared spectrum), HRMS (high resolution mass spectrum), and NMR (nuclear magnetic resonance) are applied to help characterizing the heavier components.

HRMS result shows that peak of $T_{R}$ at $32.70 \mathrm{~min}$ has a relative molecular weight of 134.24 . According to the origination of MTBE and sulfur content of the sample, elements composed of the heavy components are carbon,

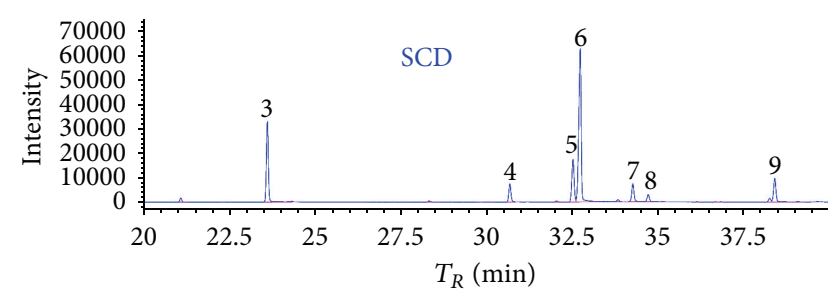

(a)

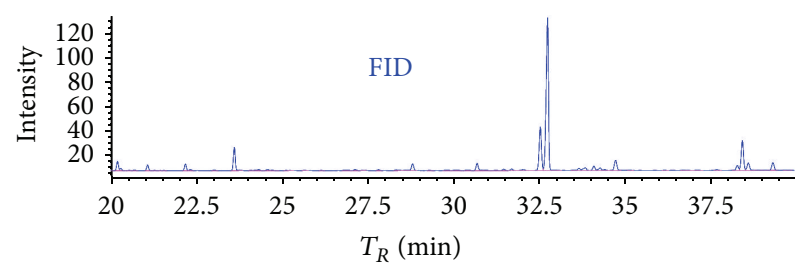

(b)

FIGURE 4: Comparison of SCD with FID for the heavy component. (a) GC-SCD for heavy component. (b) GC-FID for heavy component.

hydrogen, oxygen, and sulfur. So the molecular formula of the highest intensity in Figure 4 can be deduced as $\mathrm{C}_{6} \mathrm{H}_{14} \mathrm{OS}$. IR spectrum evidently shows the characteristic of $-\mathrm{OCH}_{3}$ and no existence of $\mathrm{R}-\mathrm{SH}$ in the sample. C13NMR of the sample indicates structure of $\mathrm{CH}_{3} \mathrm{O}_{-}, \mathrm{CHO}-,-\mathrm{CH}_{3}$, and $\mathrm{CHS}-$. So structure of the major constituent in the heavy components of MTBE03 may be<smiles>COC(C)C(C)C</smiles>

The compound is named as 2-methoxyl-3-methylthiobutane. It has two relative stereochemistries as follows:<smiles>CO[C@@H](C)[C@H](C)OC</smiles><smiles>CO[C@@H](C)C(C)C</smiles>

From the point of view of molecular configurations, the two stereochemistries should have a small difference in dipole moment. This may induce a tiny difference in retention time in GC analysis. The S, R relative stereochemistry should have a slightly larger dipole moment and so its chromatographic peak will elute a little earlier than S,S relative stereochemistry on the nonpolarity GC column. This may be the reason that there is always a pair of peaks at $32.50 \mathrm{~min}$ and $32.70 \mathrm{~min}$ for most sulfur-containing MTBE. 


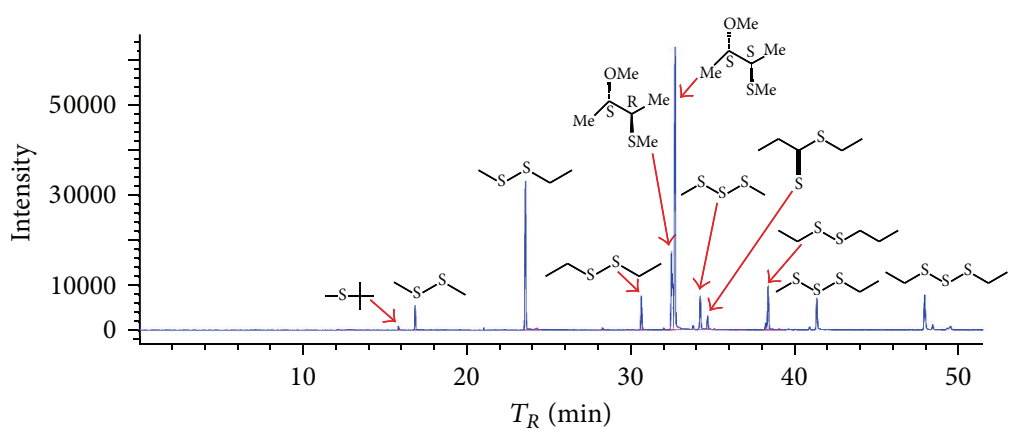

Figure 5: GC-SCD of the heavier component of MTBE03.

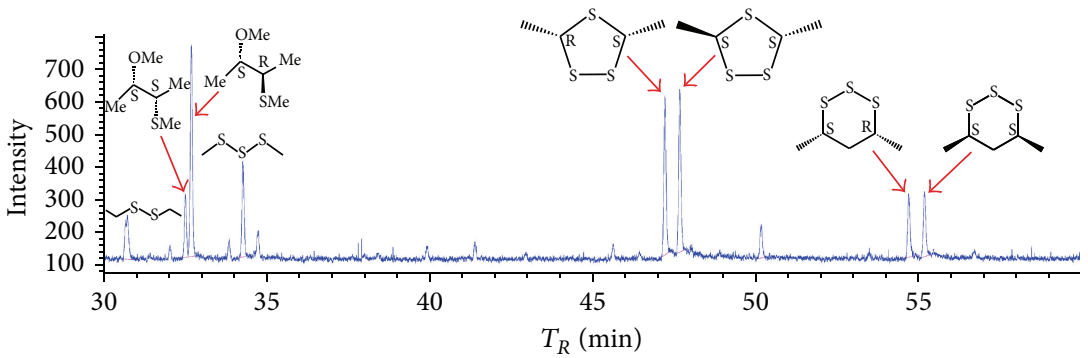

FIGURE 6: GC-MS analysis for heavy sulfur compounds in MTBE04.

By using GC-MS and standard compound calibration, other sulfur compounds in MTBE03 (Figure 3(a)) are identified individually as in Figure 5. It can be seen that in addition to<smiles>COC(C)C</smiles>

other heavy sulfur compounds in MTBE03 are mainly sulfur compounds with 2 or more sulfur atoms in one molecule; most of them are polysulfides.

It is testified in our laboratory that most of these polysulfides are generated in the LPG refining process. In the process of generating pregnant alkali solution, part of $\mathrm{S}^{2-}$ is changed to $S^{0}$, and $S^{0}$ reacts with disulfides to give polysulfides, similar to the addition reaction of $\mathrm{Na}_{2} \mathrm{~S}_{2}$ with $\mathrm{S}^{0}$ to form $\mathrm{Na}_{2} \mathrm{~S}_{x}$.

For MTBE04 in Figure 3(b), the sample is distilled first under atmosphere and then under gradually reducing pressure to control distillation liquid temperature less than $100^{\circ} \mathrm{C}$. Heavy sulfur compounds in MTBE04 are concentrated. And then through GC-MS analysis, heavy sulfur compounds have been identified and indicated in Figure 6, from which it can be found that there are three pairs of stereochemistries as main heavy sulfur compounds besides alkyl polysulfides:<smiles>CO[C@@H](C)[C@H](C)OC</smiles><smiles>C[C@@H]1SS[C@@H](C)S1</smiles><smiles>C[C@@H]1SS[C@H](C)S1</smiles><smiles>C[C@@H]1C[C@@H](C)SSS1</smiles><smiles>C[C@@H]1C[C@@H](C)SSS1</smiles>

For each pair of the stereochemistries, if existent, there is always a fixed ratio of concentrations between the two stereochemistries: $1: 3.6,1: 1$, and $1: 1$, respectively.

3.3.3. Complicated Sulfur Compounds Identified in MTBE. Besides MTBE03 and MTBE04, other 8 MTBE samples are also distilled for separating and concentrating heavy sulfur compounds. GC-MS is used to identify individual structures. In addition to structures discovered in Figures 5 and 6, more sulfur compounds are also found in MTBE samples. Identified complicated sulfur compounds are summed up in Table 3.

In fact, there are still some more sulfur compounds in MTBE which remained unidentified, especially those with high boiling point, for their contents are very low. Nevertheless, for typical domestic MTBE samples in Table 3, identified sulfur compounds account for over $95 \%$ of total sulfur in MTBE.

3.3.4. Possible Formation Ways of Heavy Sulfur Compounds in MTBE. There are many heavy sulfur compounds discovered and identified in MTBE as stated above. Their chemical 
TABLE 3: Complicated sulfur compounds found in MTBE.

\begin{tabular}{|c|c|c|c|c|c|}
\hline \multirow{2}{*}{ Sulfur compounds } & \multicolumn{5}{|c|}{ Sulfur forms, \% } \\
\hline & MTBE01 & MTBE02 & MTBE03 & MTBE04 & MTBE05 \\
\hline & 0.00379 & 0.00404 & 0.09774 & 0.0044 .3 & 0.0123 .0 \\
\hline & 0.00000 & 0.00000 & 0.00000 & 0.00000 & 0.00000 \\
\hline & 0.00000 & 0.00000 & 0.00063 & 0.00000 & 0.00000 \\
\hline & 0.00075 & 0.00086 & 0.00845 & 0.00019 & 0.00058 \\
\hline Light complicated identified sulfur & 0.00454 & 0.00490 & 0.10682 & 0.00462 & 0.01288 \\
\hline Light complicated identified sulfur, $\%$ & 86.6 & 13.8 & 31.1 & 13.5 & 17.6 \\
\hline & 0.00000 & 0.00000 & 0.00020 & 0.00000 & 0.00000 \\
\hline $\mathrm{SMe}$ & 0.00012 & 0.00013 & 0.00780 & 0.00033 & 0.00031 \\
\hline & 0.00043 & 0.00050 & 0.02891 & 0.00122 & 0.00103 \\
\hline & 0.00000 & 0.00000 & 0.00284 & 0.00060 & 0.00079 \\
\hline & 0.00000 & 0.00000 & 0.00105 & 0.00015 & 0.00027 \\
\hline & 0.00000 & 0.00000 & 0.00000 & 0.00000 & 0.00000 \\
\hline & 0.00000 & 0.00000 & 0.00289 & 0.00000 & 0.00000 \\
\hline & 0.00000 & 0.00000 & 0.00179 & 0.00000 & 0.00000 \\
\hline & 0.00000 & 0.00073 & 0.00000 & 0.00109 & 0.00049 \\
\hline & 0.00000 & 0.00074 & 0.00000 & 0.00110 & 0.00048 \\
\hline & 0.00000 & 0.00000 & 0.00215 & 0.00000 & 0.00000 \\
\hline & 0.00000 & 0.00000 & 0.00000 & 0.00000 & 0.00033 \\
\hline
\end{tabular}


TABLe 3: Continued.

\begin{tabular}{|c|c|c|c|c|c|}
\hline \multirow{2}{*}{ Sulfur compounds } & \multicolumn{5}{|c|}{ Sulfur forms, \% } \\
\hline & MTBE01 & MTBE02 & MTBE03 & MTBE04 & MTBE05 \\
\hline & 0.00000 & 0.00015 & 0.00000 & 0.00046 & 0.00024 \\
\hline & 0.00000 & 0.00015 & 0.00000 & 0.00046 & 0.00023 \\
\hline Heavy complicated sulfur & 0.00055 & 0.00240 & 0.04743 & 0.00541 & 0.00417 \\
\hline Heavy complicated sulfur, \% & 10.5 & 6.7 & 13.8 & 15.8 & 5.7 \\
\hline Total unidentified sulfur & 0.00015 & 0.00005 & 0.00438 & 0.00160 & 0.00246 \\
\hline Total unidentified sulfur, $\%$ & 2.9 & 0.1 & 1.3 & 4.7 & 3.4 \\
\hline Total sulfur in MTBE & 0.00524 & 0.03557 & 0.34443 & 0.03424 & 0.07329 \\
\hline
\end{tabular}

structures are very different from those in LPG or C4. Most of these sulfur compounds may be formed in the process of etherifying isobutene with methanol.

Generally, there is about $0.1-0.5 \%$ of 1,4 -diene in stock C4. In etherification process, methanol is the other stock. If there is even trace methanethiol in stock $\mathrm{C} 4$, a reaction may occur to a certain degree:

(4)

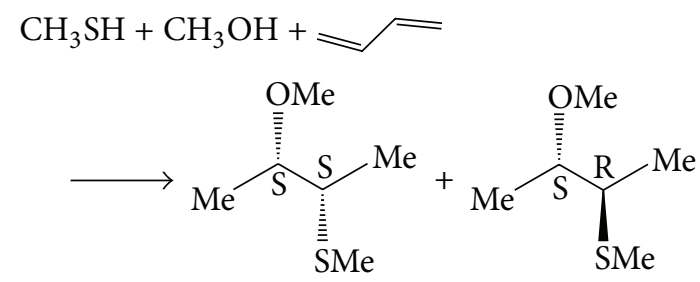

Reaction product is 2-methoxyl-3-methylthio-butane. Considering steric hindrance, relative stereochemistry S,R type may have more production than S,S type.

In stock $\mathrm{C} 4$, especially $\mathrm{C} 4$ originated from coking process, there is likely trace ethenethiol $\left(\mathrm{CH}_{2}=\mathrm{CH}-\mathrm{SH}\right)$. In the refining process of LPG, it will be transferred to aqueous alkali phase and then in the regeneration unit easily converted to oil soluble divinyl disulfide under the oxygenation of trace oxygen, and part of that will get back to refined LPG when treating LPG with this regenerated alkali. Elemental sulfur $S^{0}$ can be produced by oxidation of $\mathrm{S}^{2-}$ in the alkali and often exists in refined LPG [11]. Either oxygen or $S^{0}$ can oxidize thiols to disulfide and produce trace $\mathrm{H}_{2} \mathrm{~S}$. And $\mathrm{H}_{2} \mathrm{~S}$ can react with divinyl disulfide to generate

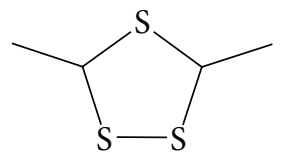

see $[12]$ :
(5)

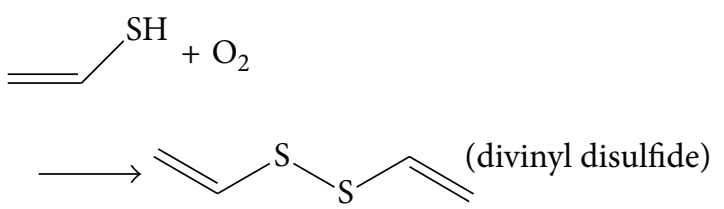

(6) $\mathrm{S}+\mathrm{RSH} \longrightarrow \mathrm{RSSR}+\mathrm{H}_{2} \mathrm{~S}$

(7)

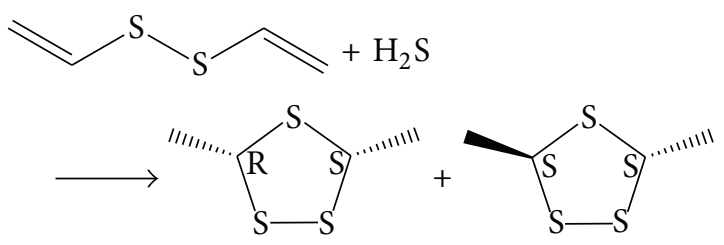

The reaction may be symmetrical and relative stereochemistry S,R type may have the same production as S,S type.

For 4,6-dimethyl-1,2,3-trithiane,<smiles>CC1CC(C)SSS1</smiles>

no clue on its synthesis can be found in literatures. It may be formed by a cyclization reaction of a trisulfide with an olefin.

There are many kinds of polysulfides in MTBE. It can be understood that, in the regeneration process of alkali used for LPG refining process, $\mathrm{S}^{2-}$ in the alkali is oxidized to elemental sulfur $S^{0}$. The latter further reacts with disulfides generated in the same time to form polysulfides:

(8) $\mathrm{RSSR}^{\prime}+(n-2) \mathrm{S} \longrightarrow \mathrm{RS} \mathrm{R}^{\prime}$

where $n=3 \sim 5$ usually. This has been testified by a special Merox process in our laboratory by using unregenerated alkali containing mercaptide of $\mathrm{RS}^{-}$with additional excess of sulfion of $\mathrm{S}^{2-}$ under the catalysis of cobalt phthalocyanine 


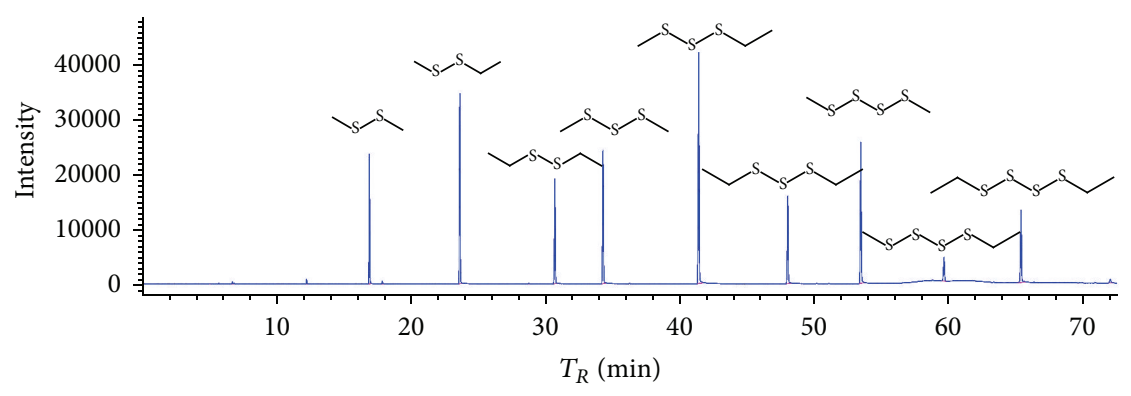

FIGURE 7: GC-SCD of generated polysulfides.

sulfonates and oxidized by the air. The GC-SCD characteristic is shown in Figure 7.

It can be found in Figure 7 that a series of polysulfides are generated, including di-, tri-, tetra-, and even pentasulfides. That means that, under excess of $\mathrm{S}^{2-}$, a Merox process can produce polysulfide series [13]. Polysulfides formed in alkali are oil soluble and part of them will return to and dissolve in LPG when recycled regenerated alkali is used to contact undemercaptaned LPG. Because polysulfides have very high boiling point and enough thermal stability at temperature lower than $120^{\circ} \mathrm{C}$, dissolved polysulfides in LPG will first stay in $\mathrm{C} 4$ after gas distillation process and then reside in the mixture of MTBE, surplus methanol, and unreacted C4 after etherification reaction and at last be concentrated in MTBE after catalysis distillation process.

However, there are still $1-5 \%$ sulfur compounds in total sulfur in MTBE remaining unidentified. Structures and forming mechanisms of these sulfur compounds are also kept unrevealed and may be worthy of further study in the future.

\section{Conclusions}

(1) Nearly 50 MTBE samples from refineries are analyzed, and over $95 \%$ of sulfur compounds in sulfur content are identified.

(2) All sulfur compounds in MTBE can be classified into three sources: common sulfur compounds, newly formed sulfur compounds, and heavy sulfur compounds.

(3) Common sulfur compounds in MTBE are mainly low molecule mercaptans, sulfides, and dialkyl disulfides. They come directly from refined LPG or C4 and usually account for $50-70 \%$ of total sulfur in MTBE.

(4) Newly formed sulfur compounds are almost wholly thioetherification products of thiols with butenes in the etherification process of $\mathrm{C} 4$ with methanol. This part of sulfur usually accounts for $10-30 \%$ of total sulfur in MTBE, occasionally for over $80 \%$.

(5) Sulfides with high boiling point are mainly polysulfides and oxygen-containing sulfur compounds. These sulfur compounds may be generated by addition reaction of elemental $S$ to disulfides and by addition reaction of methanol and methanethiol to 1,3-diene. They usually account for $5-15 \%$ of total sulfur in MTBE.

\section{Conflict of Interests}

The authors declare that there is no conflict of interests regarding the publication of this paper.

\section{References}

[1] GB17930-2013, Gasoline for Vehicle in China, General Administration of Quality Supervision, Inspection and Quarantine of the People's Republic of China, Standardization Administration of the People's Republic of China, 2013.

[2] C. Bradley and D. J. Schiller, "Determination of sulfur compound distribution in petroleum by gas chromatography with a flame photometric detector," Analytical Chemistry, vol. 58, no. 14, pp. 3017-3021, 1986.

[3] M. Anderson and R. C. Dimmer, "Analyze trace sulfur compounds in hydrocarbon gas streams," Hydrocarbon Processing, vol. 76, no. 4, pp. 73-80, 1997.

[4] G. Castello, G. D’Amato, and M. Nicchia, "Gas chromatographic determination of traces of light hydrocarbons and sulphur compounds in gases at low pressure by the simultaneous use of flame ionization and flame photometric detectors," Journal of Chromatography, vol. 521, no. 1, pp. 99-107, 1990.

[5] Z. Wei Xinming, "Chemical form identification of Trace sulfides in LPG," Petroleum and Natural Gas Industry, vol. 32, no. 5, pp. 318-320, 2003.

[6] K. J. Rygle, G. P. Feulmer, and R. F. Scheideman, "Gas chromatographic analysis of mercaptan odorants in liquefied petroleum gas," Journal of Chromatographic Science, vol. 22, no. 11, pp. 514$519,1984$.

[7] L. Yongmei, "Determination of sulfur compounds in liquefied petroleum gas by large-bore capillary gas chromatography," Journal of Instrumental Analysis, vol. 19, no. 4, pp. 63-64, 2004.

[8] ASTMD5504-12, Standard Test Method for Determination of Sulfur Compounds in Natural Gas and Gaseous Fuels by Gas Chromatography and Chemiluminescence.

[9] Y. Huang, "Measurements to reduce sulfur content in MTBE," Contemporary Chemical Industry, vol. 43, no. 4, pp. 551-554, 2014.

[10] H. Wang and X. Chen, "Industrial application of MTBE extractive distillation desulfurizing technology," Shandong Chemical Industry, vol. 42, no. 10, pp. 128-129, 2013. 
[11] X. Fu, F. Cao, W. Huang, and T. Li, "Determination of elemental sulfur in liquefied gas by gas chromatography," Petroleum Processing and Petrochemicals, vol. 35, no. 12, pp. 57-59, 2004.

[12] Z. Liang, X. Yingnan, and L. Yong, "Simple method for synthesizing 3,5-dimethyl-1,2,4-trithiolane," Faming Zhuanli Shenqing, CN101824026, China.

[13] Faming Zhuanli Shenqing, in Application, China. 


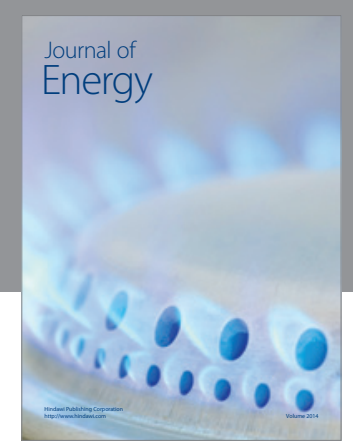

Journal of

Industrial Engineering
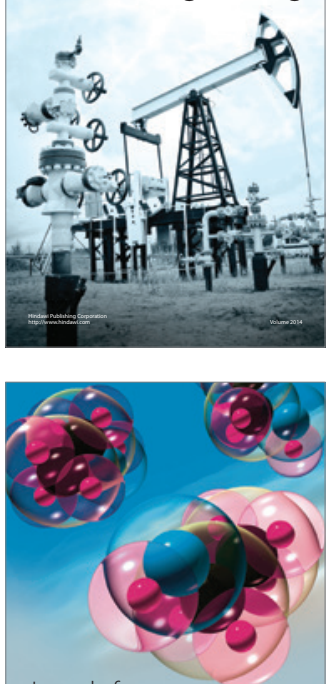

Fuels
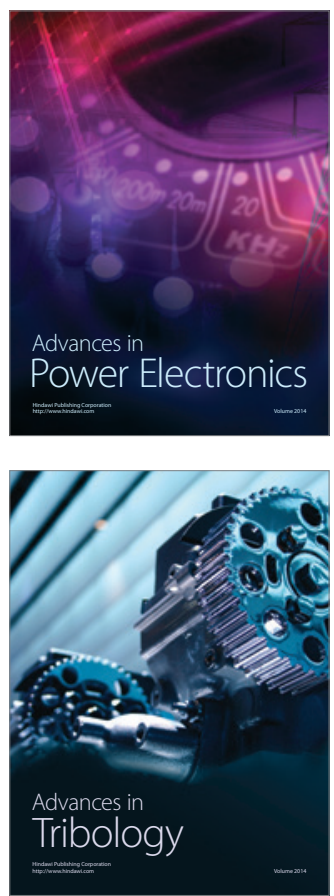

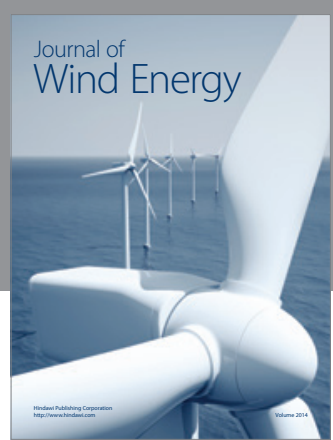

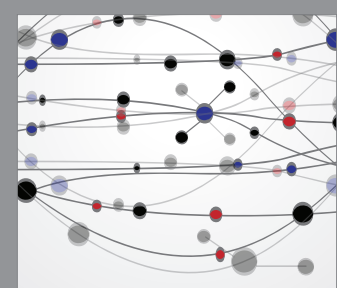

The Scientific World Journal

Submit your manuscripts at http://www.hindawi.com

Journal of

Structures
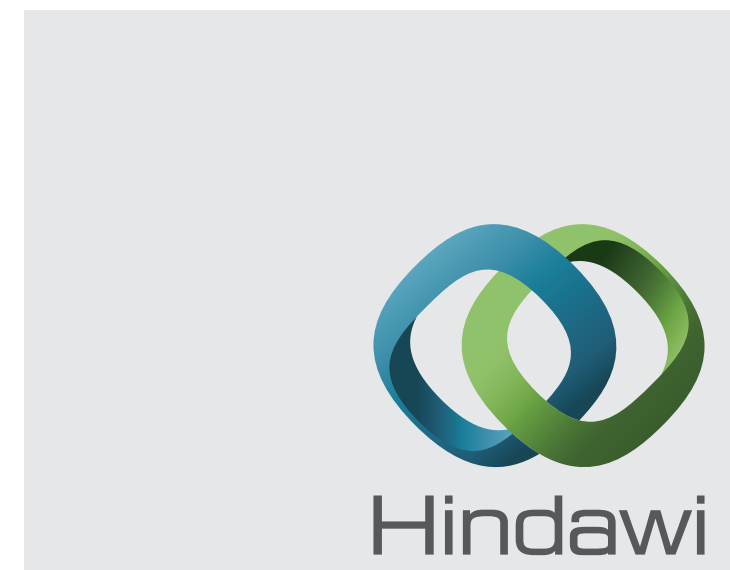

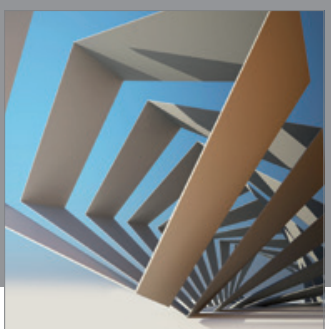

Rotating

Machinery
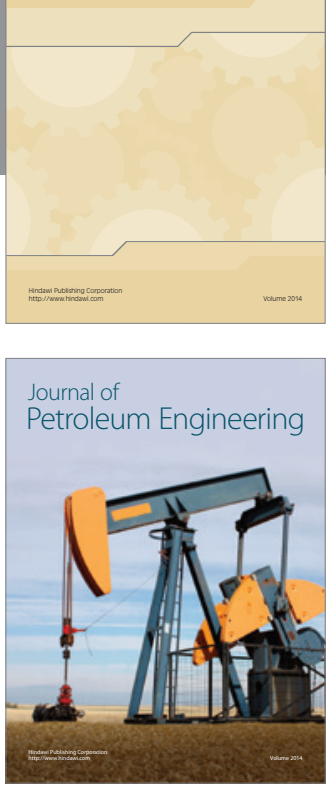

Journal of

Solar Energy
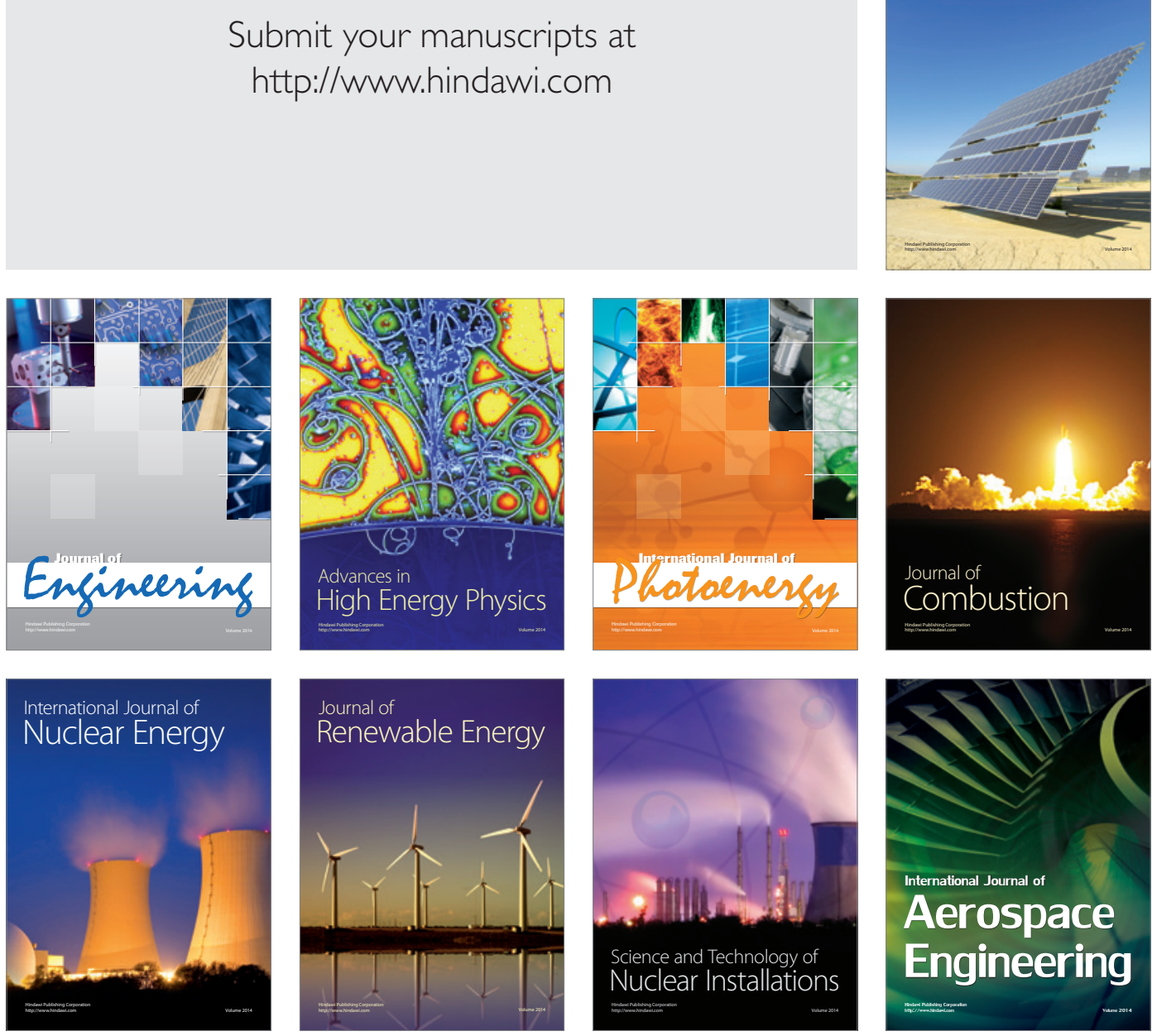